\title{
Concomitant novel ALK-SSH2, EML4-ALK and ARID2-ALK, EML4-ALK double-fusion variants and confer sensitivity to crizotinib in two lung adenocarcinoma patients, respectively
}

\author{
Hong Tao ${ }^{1}$, Zhe Liu', Jing Mu², Fei Gai ${ }^{3}$, Zhan Huang ${ }^{3}$ and Liang Shi ${ }^{*}$
}

\begin{abstract}
Introduction: Anaplastic lymphoma kinase (ALK) gene rearrangements, have been identified in approximately 2-7\% of patients with lung adenocarcinoma (LUAD). However, co-occurrence of double ALK fusions in one patient was rare. Herein, we reported two Chinese female LUAD patients with confirmed double ALK fusion variants by next generation sequencing.

Case presentation: Case 1, a 38-year-old female was diagnosed as peripheral LUAD in left upper lobe with synchronous multiple intrapulmonary metastases (pT2NOM1b, stage IVa). And case 2, a 58-year-old female had left lower lobe primary LUAD and synchronous multiple lung metastases (pT4N2M1b, stage IVa). In both patients, tumor cells displayed strong expression of ALK protein. Genetic profiling by next generation sequencing showed both patients concurrently harbored two types of ALK rearrangements. Case 1 had an unreported ALK-SSH2/EML4-ALK double fusions, and case 2 had an another novel ARID2-ALK/EML4-ALK double fusions. Both of these patients responded to ALK inhibitor crizotinib.
\end{abstract}

Conclusions: Our study reported two novel ALK fusion partners never reported, which expands the knowledge of ALK fusion spectrum and provides insight into therapeutic options for patients with double ALK fusions.

Keywords: Lung adenocarcinoma, Anaplastic lymphoma kinase fusion, ALK-SSH2, ARID2-ALK, Targeted therapy

\section{Introduction}

Anaplastic lymphoma kinase $(A L K)$ rearrangement is a well-known driver present in 3-7\% of non-small-cell lung cancer (NSCLC) patients [1]. It create an oncogenic ALK tyrosine kinase, which activates many downstream signaling pathways, leading to increased cell proliferation and survival [2]. In addition, $A L K$ rearrangement

\footnotetext{
* Correspondence: shiliang@bjmu.edu.cn

'Department of Oncology, Beijing Chest Hospital, Capital Medical University, Beijing Tuberculosis and Thoracic Tumor Research Institute, Beijing, China Full list of author information is available at the end of the article
}

enriched in younger aged adenocarcinoma patients who never smoked or are light smokers. Up to date, various $A L K$ fusion partners have been discovered, including $E M L 4, K I F 5 B, K L C 1, T F G$, and others [3, 4]. Ongoing efforts also identified $A L K$ fusions in other epithelial malignancies, such as CLIP1-ALK, KIF5B-ALK, and KIAA1217-ALKfusions in renal cell carcinoma [5], $B A B A M 2-A L K$ fusion in gynecologic clear cell carcinomas [6], STRN-ALK, PPP1R21-ALK, and SENPF$A L K$ fusions in colorectal carcinoma [7], and STRN$A L K$, and TPM1-ALK fusions in peritoneal

(c) The Author(s). 2022 Open Access This article is licensed under a Creative Commons Attribution 4.0 International License, which permits use, sharing, adaptation, distribution and reproduction in any medium or format, as long as you give appropriate credit to the original author(s) and the source, provide a link to the Creative Commons licence, and indicate if changes were made. The images or other third party material in this article are included in the article's Creative Commons licence, unless indicated otherwise in a credit line to the material. If material is not included in the article's Creative Commons licence and your intended use is not permitted by statutory regulation or exceeds the permitted use, you will need to obtain permission directly from the copyright holder. To view a copy of this licence, visit http://creativecommons.org/licenses/by/4.0/ The Creative Commons Public Domain Dedication waiver (http://creativecommons.org/publicdomain/zero/1.0/) applies to the data made available in this article, unless otherwise stated in a credit line to the data. 
mesothelioma [8]. With the popularity of nextgeneration sequencing (NGS) technology, more and more rare rearrangement types will be discovered. Application of ALK targeting tyrosine kinase inhibitors such as crizotinib [9], ceritinib [10], alectinib [11], and brigatinib [12], have largely improved prognosis as well as life quality of $A L K$ fusion-positive NSCLC patients.

Although novel $A L K$ fusion variants have been occasionally reported in NSCLC, to our knowledge, the concomitance of double $A L K$ fusion variants in the same lung adenocarcinoma (LUAD) patient was rare, by far, only 6 cases were reported, median age was 44 (range, 29-64 years). The majority of these patients were ever, or current smokers $(4 / 5,80 \%)$ (Table 1) [13-18]. Notably, different fusion partners can impact the response to ALK inhibition in patients with NSCLC $[19,20]$. Limited evidence is available on the response to TKI treatment from patients with double $A L K$ fusions. Here we reported two novel $A L K$ fusion variants concurrently with $E M L 4-A L K$ in two LUAD patients respectively (both were female and non-smoker), and both of the patients were sensitive to crizotinib treatment.

\section{Case report}

\section{Case 1}

The patient was a 38-year-old Chinese female without a history of smoking. The timeline of her diagnosis and treatment was shown in Fig. $1 \mathrm{~A}$ and the detailed description was as follows. In 2008, during a routine physical examination in our hospital, chest radiography revealed a left lung shadow without defined diagnosis. In August 2012, a computed tomography (CT) scan revealed a mass in the upper lobe of the left lung with bilateral multiple intrapulmonary metastases (Fig. 1B). This patient underwent thoracoscopic left upper lobectomy on September 12th, 2012. Postoperative diagnosis showed left upper lung adenocarcinoma, pT2N0M1b, stage IVa (Fig. 2 A). Three months after surgery, from January 2013 to October 2013, she received pemetrexed plus cisplatin chemotherapy for 4 cycles, pemetrexed maintenance treatment for 4 cycles, and the diseases remained stable. Disease progressed with increased lung lesions in December 2013 (fourteen months after surgery) (Fig. 1 C). Subsequently, this patient received 2 cycles of chemotherapy of paclitaxel plus cisplatin. To seek more potential treatments, in December 2013, immunohistochemistry was performed in postoperative formalin fixed paraffin-embedded (FFPE) tissues, and the tumor cells were positive for ALK D5F3 (Ventana Medical Systems Inc., Oro Valley, AZ, USA). Subsequently, next-generation sequencing (NGS) in a range of 76 cancer-related genes was performed in the FFPE specimen (DNA-based detection, Amoy Diagnostics, Xiamen, China). Revealing coexistence of double $A L K$ fusion: EML4-ALK (E6:A20, MAF $=24.7 \%)$ and ALK-SSH2 (A19:S3, MAF $=0.85 \%$ ) (Fig. 2B), which was further validated by another NGS 10 cancer-related gene panel (RNA-based detection for fusion genes, Amoy Diagnostics, Xiamen, China), EML4-ALK ALK-SSH2 (E6:A20, $\mathrm{MAF}=25.6 \% ; \mathrm{A} 19: \mathrm{S} 3, \mathrm{MAF}=0.68 \%$, respectively) (Fig. 2 C). This patient was treated with crizotinib (250 mg twice daily) staring from December 31th, 2013. Chest CT scan after one-month treatment indicated a partial response (PR) to crizotinib (Fig. 1D). Dosage of crizotinib was gradually de-escalated to $250 \mathrm{mg}$ once a day in the following 2 months due to increased myocardial enzyme, and the lesions continued to shrink (Fig. 1E). After 2 months of targeted therapy, in March 2014, chest CT showed that the lesion in the left lung was slightly enlarged, and the metastasis in both lungs had no obvious change from the last time (Fig. $1 \mathrm{~F}$ ). However, crizotinib was discontinued on April 7th, 2014 due to treatment-related adverse events, such as myocardial damage, gastrointestinal reactions, and visual disturbance. This patient died in September 2014 attributing to disease progressing, and having attained an overall survival of 24.9 months.

\section{Case 2}

This patient was a 58-year-old Chinese female with no history of smoking. The timeline of her diagnosis and treatment was shown in Fig. 3 A and the detailed description was as follows. She was referred to our hospital in June 2014, complaining of breath shortness. A chest CT scan revealed a mass $(4.5 \times 3.0 \times 3.0 \mathrm{~cm})$ in the left lower lobe with bulky swollen mediastinal and multiple

Table 1 Summary of the characteristics of patients with double ALK fusions reported in previous case reports

\begin{tabular}{lllllll}
\hline Ref. & Study & Age & Gender & Smoking & ALK fusion variants & Response to crizotinib \\
\hline$[13]$ & Xuan Wu, et al. 2020 & 32 & Male & Smoker & CCNY-ALK, and ATIC-ALK & Yes \\
{$[14]$} & Xueqian Wu, et al. 2020 & 64 & Female & Non-smoker & NLRC4-ALK, and EML4-ALK & Yes \\
{$[15]$} & Jing Luo, et al. 2019 & 44 & Male & Smoker & PRKCB-ALK, and EML4-ALK & Yes \\
{$[16]$} & Bao Dong Qin, et al. 2019 & 29 & Male & Smoker & EML4-ALK, and BCL11A-ALK & Yes \\
{$[17]$} & Hao Lin, et al. 2018 & 56 & Male & Not available & EML6-ALK, and FBXO11-ALK & Yes \\
[18] & Jinping Yin, et al. 2018 & 44 & Male & Smoker & DYSF-ALK, and ITGAV-ALK & Yes \\
\hline
\end{tabular}



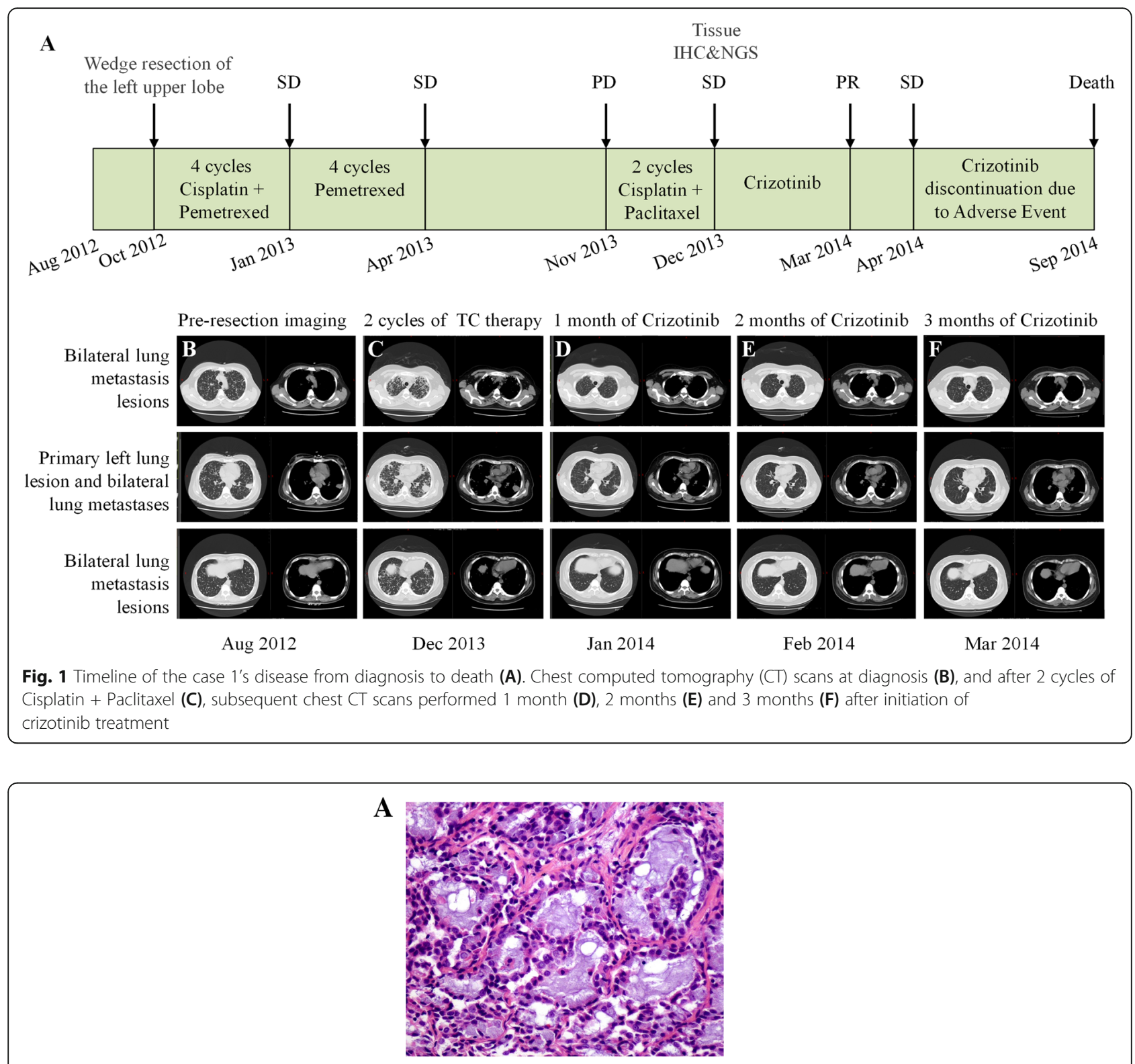

B

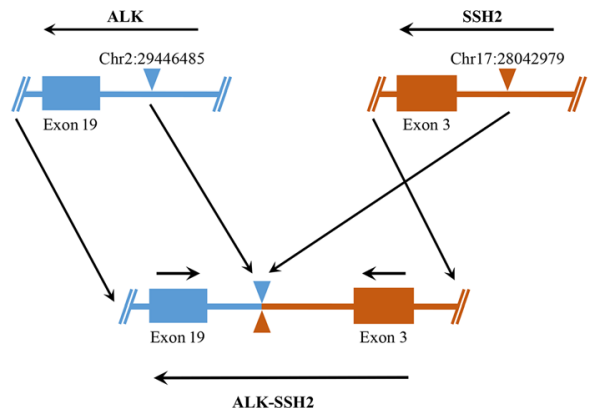

C

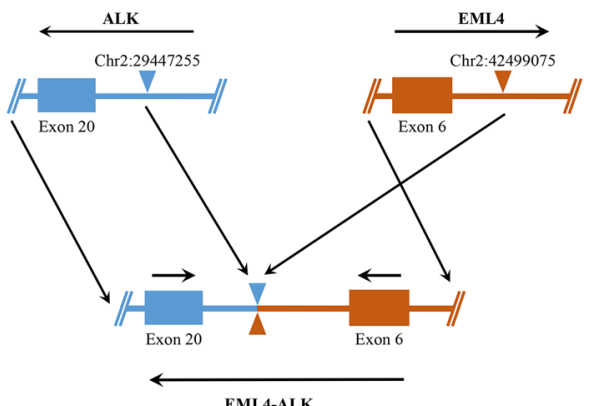

Fig. 2 Pathological examination and schematic diagram of ALK rearrangement of case 1. (A) Hematoxylin and eosin (H\&E) staining of the left upper lobe revealed adenocarcinoma ( $\times$ 400). (B) A breakpoint within ALK (shown in blue) intron 19 at chromosome 2 was fused within SSH2 (shown in red) intron 2 at chromosome 17, giving rise to the ALK-SSH2 fusion gene. (C) A breakpoint within ALK (shown in blue) intron 19 at chromosome 2 was fused within EML4 (shown in red) intron 6 at chromosome 2, but have opposite orientations, giving rise to the EML4-ALK fusion gene 


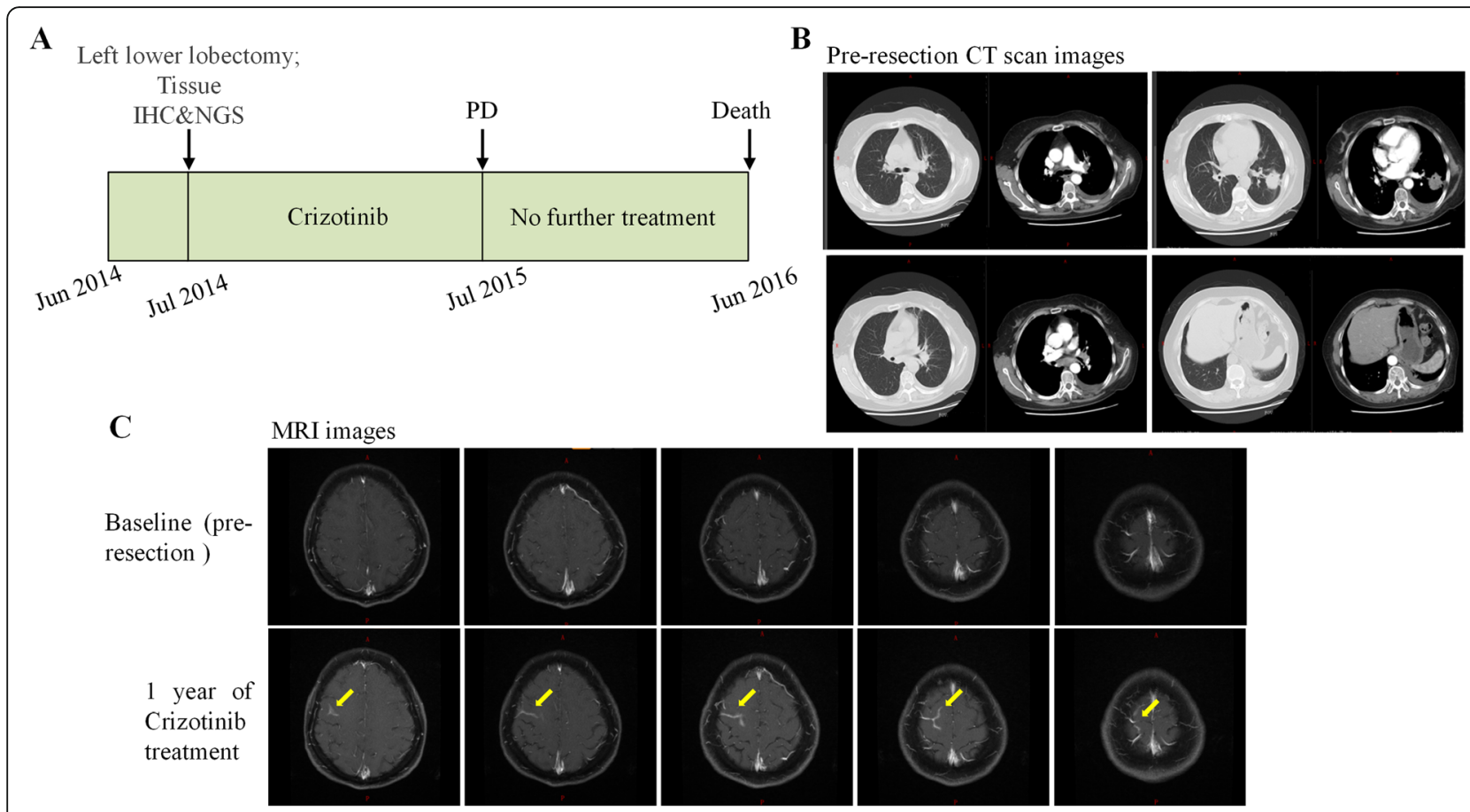

Fig. 3 Timeline of the case 2's disease from diagnosis to death (A). Chest computed tomography (CT) scans at diagnosis (B), and brain magnetic resonance imaging images at baseline (upper panel) and after crizotinib treatment (lower panel) (C). The yellow arrow indicates a new meningeal metastasis lesion

nodules in bilateral lung lobes (Fig. 3B). On July 11th, 2014, this patient underwent left lower lobectomy with multifocal resection. Pathological diagnosis indicated a typical lung adenocarcinoma (pT4N2M1b, stage IVa) (Fig. 4 A). Immunohistochemistry of ALK D5F3 (Ventana Medical Systems Inc., Oro Valley, AZ, USA) was positive (Fig. 4B). A NGS analysis to the FFPE specimen using a 76 cancer-related gene panel (DNA-based detection, Amoy Diagnostics, Xiamen, China) revealed a double ALK fusion: EML4-ALK ARID2-ALK (E20:A20, $0.99 \%$ abundance; and A12:A23, $1.67 \%$ abundance) (Fig. 4 C), which was confirmed by another NGS 10 cancer-related gene panel (RNA-based detection for fusion genes, Amoy Diagnostics, Xiamen, China), the results also showed a double ALK fusion: EML4-ALK ARID2ALK (E20:A20, 0.81\% abundance; and A12:A23, 1.09\% abundance) (Fig. 4D). The patient was treated with crizotinib $250 \mathrm{mg}$ twice daily in July 31th, 2014 (20 days after surgery), the disease was progressed with meningeal metastasis after 12 months' treatment duration (Fig. 3 C). Unfortunately, she was unable to receive any further treatment due to financial issue. Finally, the patient died in June 28th, 2016, having attained an overall survival of 23.9 months.

\section{Discussion}

$A L K$ gene rearrangement is an important driving oncogene in NSCLC. Several different forms of ALK fusions have been reported, including $E M L 4-A L K$, the most common $A L K$ fusion in NSCLC, which contains the 5' end of EML4 fused to the entire ALK kinase domain and leads to constitutive ligand independent kinase activation [1]. However, the patients who harbor double $A L K$ fusion variants are extremely rare. Few investigations have focused on the concomitance of double $A L K$ rearrangements because of the low incidence. According to our literature search results, only Six cases have been previously reported, including $C C N Y-A L K$, and $A T I C-$ $A L K$ [13], NLRC4-ALK, and EML4-ALK [14], PRKCB$A L K$ and EML4-ALK [15], EML4-ALK and BCL11A$A L K[16], E M L 6-A L K$, and FBXO11-ALK [17], as well as $D Y S F-A L K$ and ITGAV-ALK [18]. ALK-TKIs have been widely used for $A L K$-positive patients, but the responses are heterogeneous for patient with different $A L K$ fusions. The clinical-pathological characteristics and the response to ALK-TKIs of such patients with double fusion variants remain unclear, the effectiveness of ALK-TKI treatment might be affected by the two kinds of $A L K$ mutations exist simultaneously in one patient. Here, we identified two novel double $A L K$ fusion variants in two LUAD patients respectively, both patients were nonsmoking female, one was 38 years old and the other was 58 years old at the time of diagnosis.

Previous reports confirmed that patients with double $A L K$ fusion may respond to crizotinib [14-18]. In this report, the patients with double $A L K$ fusions were also 

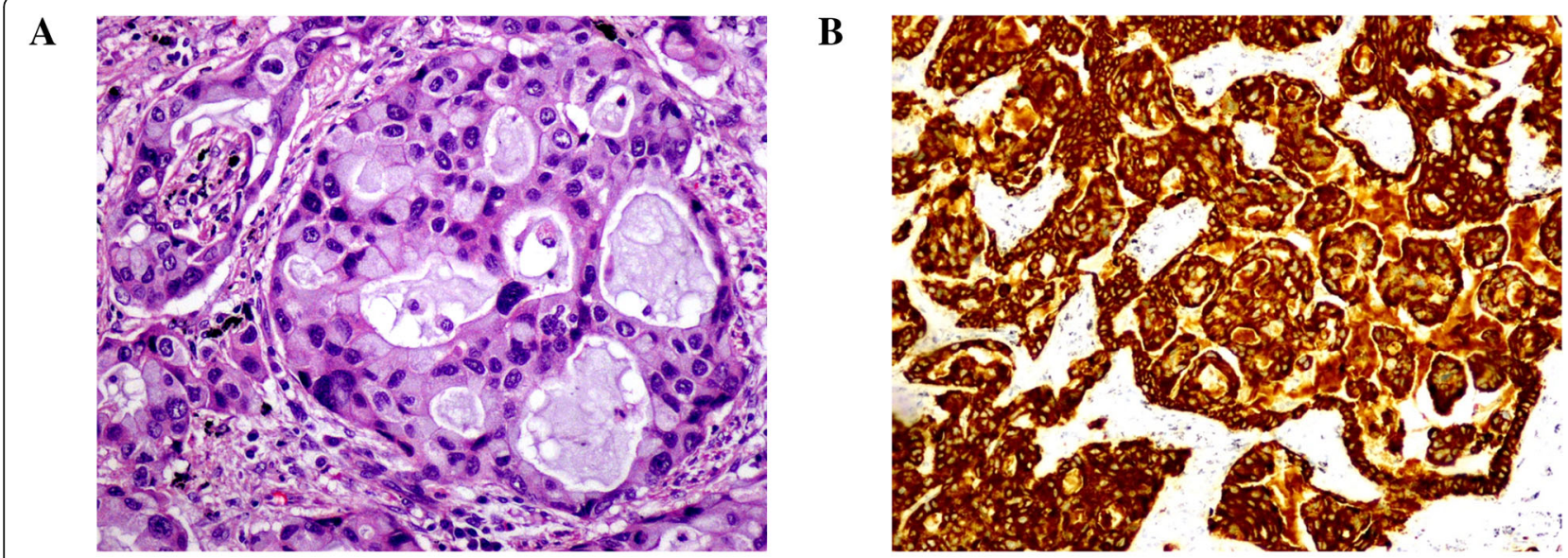

C

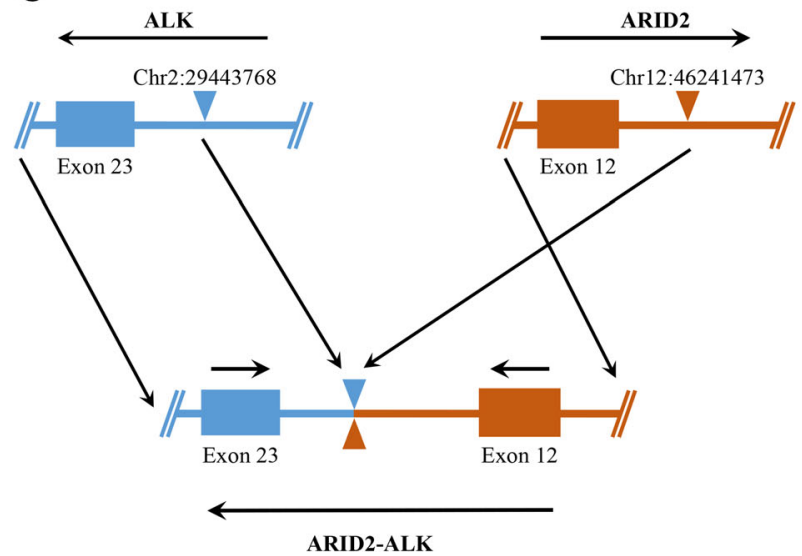

D

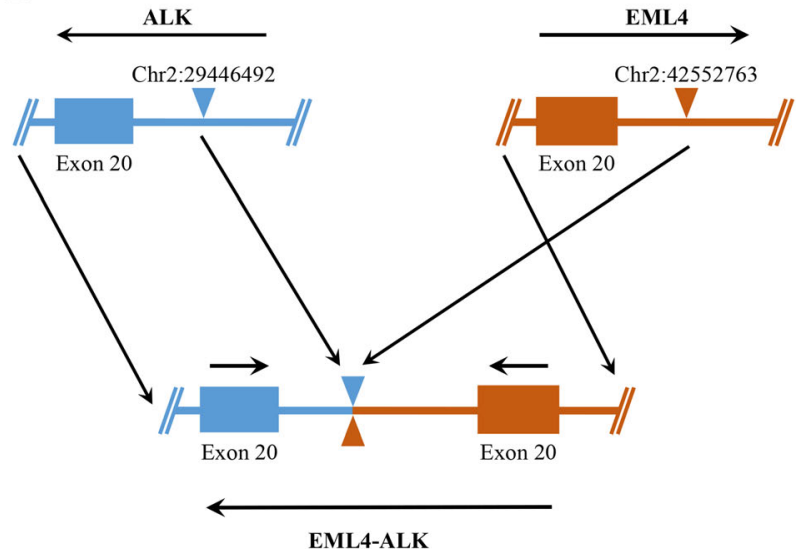

EML4-ALK

Fig. 4 Pathological examination, immunostaining of ALK in postoperative tumor tissue and schematic diagram of ALK rearrangement of case 2. (A) H\&E staining of the left lower lobe revealed adenocarcinoma ( $\times 400)$. (B) Immunostaining for ALK D5F3 with strong granular cytoplasmic staining ( $\times 200$ ). (C) A breakpoint within ALK (shown in blue) intron 22 at chromosome 2 was fused within ARID2 (shown in red) intron 12 at chromosome 12, giving rise to the ARID2-ALK fusion gene. (D) A breakpoint within ALK (shown in blue) intron 19 at chromosome 2 was fused within EML4 (shown in red) intron 20 at chromosome 2, but have opposite orientations, giving rise to the EML4-ALK fusion gene

sensitive to crizotinib, and two novel $A L K$ fusions: ALKSSH2 and ARID2-ALK were detected. Case 1 was diagnosed at advanced stage and received multiline chemotherapy, without condition improvement; instead, bone metastases developed. Except EML4-ALK, ALK-SSH2 was uncovered. Slingshot 2 (SSH2) belongs to a gene family of three members (SSH1, SSH2, and SSH3), it has been shown to control some essential cellular processes, including invasion, migration, and motility [21]. In ALK$\mathrm{SSH} 2$ fusion, the fusion point falls into intron 2 of $\mathrm{SSH} 2$ and the promoter region was retained. As for $A L K$, the entire intracellular kinase domain was retained. And it is well known that the fusion leading to constitutive kinase activation can be a powerful driving force for oncogenesis. Thus, it is speculated that the concomitance of $A L K-S S H 2$ fusion maybe one of the reasons for sensitivity to crizotinib. Case 2 with another novel $A L K$ fusion variant, $A R I D 2-A L K$, was presented a $\mathrm{SD}$ to crizotinib for about 1 year, and progressed with meningeal metastasis. ARID2 encode nuclear proteins containing a DNA-binding domain called AT-rich interaction domain (ARID domain), and is implicated in chromatin remodeling. ARID2 was found mutated in hepatocellular carcinoma [22], melanoma [23] and lung carcinoma [24]. Given that the mutation abundance of EML4-ALK was very low (less than $1 \%$ ), so it is speculated that the coexistence of ARID2-ALK fusion maybe one of the reasons for response to crizotinib in this patient.

The most common adverse events in clinical trials with crizotinib were visual disorders, nausea-vomiting, diarrhea, edema, and elevated transaminases [25]. Due to the increasing clinical experience with crizotinib, other toxicities are emerging, such as QT interval prolongation, bradycardia, hypogonadism, renal impairment, renal cysts and hypersensitivity [26-29]. The treatmentrelated adverse events that occurred in case 1 had been reported in aforementioned clinical trials. After reducing the drug dose, grade 1-2 adverse events including 
diarrhea and visual disturbance were all alleviated. Unfortunately, crizotinib treatment was eventually stopped due to un-tolerable adverse events in case 1 , mainly because of the myocardial damage.

Case 2 remained stable during crizotinib treatment, but brain metastasis occurred after 1 year of treatment. As a drive gene mutation, $A L K$ gene rearrangement accounts approximately $7 \%$ of all cases of NSCLC. And these patients achieve prolonged PFS when treated with crizotinib, a first-generation ALK-targeted tyrosine kinase inhibitor. However, most patients experience tumor recurrence within 1 year after crizotinib therapy. Moreover, brain metastasis, which remains a substantial cause of morbidity and mortality, is the most common type of recurrence [30, 31].

In this study, both patients responded to crizotinib treatment. The first patient gave up the treatment due to intolerable treatment-related adverse events, while the second patient occurred brain metastasis after one year of treatment, and also gave up the follow-up due to economic reasons. Since there were no specific research results to support, we can only speculate that coexistence of double $A L K$ fusion may be related to the occurrence of serious adverse events or drug resistance.

There are some limitations in our present study. First, the case 2 did not receive subsequent treatment such as chemotherapy and radiotherapy, which might have an impact on her overall survival. Second, the biological function of ALK-SSH2 and ARID2-ALK should be further investigated using cell lines and animal models after molecular manipulation of ALK-SSH2 and ARID2-ALK.

In conclusion, this study is described two novel $E M L 4$ $A L K$ ALK-SSH2, and EML4-ALK ARID2-ALK double $A L K$ fusion variants LUAD patients. And the curative effect of crizotinib in the treatment of these patients provided a certain reference for the patients with such gene alterations. In addition, the NGS assay provides a reliable diagnostic tool for the detection of novel fusion partner genes for $A L K$-rearranged in patients with lung adenocarcinoma.

\section{Acknowledgements}

We are grateful to all the investigators and patients in this study.

\section{Authors' contributions}

Hong Tao, Zhe Liu, Jing Mu, and Liang Shi managed and treated the patient; Hong Tao, Fei Gai and Zhan Huang wrote the paper. All authors read and approved the final manuscript.

\section{Funding}

This research was supported by Science and Technology Project of Beijing Municipal Education Commission (No. 11620196).

\section{Availability of data and materials}

All data generated or used during the study are available from the corresponding author by request.

\section{Declarations}

Ethics approval and consent to participate

This research was approved by the Ethics Committee of Beijing Chest Hospital, Capital Medical University in December 2011. Informed consent was granted from the two patients' next of kin to publish the present data as a case report.

\section{Competing interests}

Fei Gai and Zhan Huang were employed by Amoy Diagnostics Co., Ltd. No other potential conflicts of interest relevant to this article were reported.

\section{Author details}

${ }^{1}$ Department of Oncology, Beijing Chest Hospital, Capital Medical University, Beijing Tuberculosis and Thoracic Tumor Research Institute, Beijing, China

${ }^{2}$ Department of Pathology, Beijing Key Laboratory for Drug Resistant

Tuberculosis Research, Beijing Chest Hospital, Capital Medical University,

Thoracic Tumor Research Institute, Beijing Tuberculosis, Beijing, China.

${ }^{3}$ Department of Medical Business, Amoy Diagnostics Co., Ltd, Xiamen, China.

Received: 21 October 2021 Accepted: 25 January 2022

Published online: 10 February 2022

\section{References}

1. Golding B, Luu A, Jones R, Viloria-Petit AM. The function and therapeutic targeting of anaplastic lymphoma kinase (ALK) in non-small cell lung cancer (NSCLC). Mol Cancer Feb. 2018;19(1):52. doi:https://doi.org/10.1186/s12943018-0810-4. 17 ) .

2. Chiarle R, Voena C, Ambrogio C, Piva R, Inghirami G. The anaplastic lymphoma kinase in the pathogenesis of cancer. Nature reviews Cancer Jan. 2008;8(1):11-23. doi:https://doi.org/10.1038/nrc2291.

3. Du X, Shao Y, Qin HF, Tai YH, Gao HJ. ALK-rearrangement in non-small-cell lung cancer (NSCLC). Thorac Cancer Apr. 2018;9(4):423-30. doi:https://doi. org/10.1111/1759-7714.12613.

4. Chen HF, Wang WX, Xu CW, et al. A novel SOS1-ALK fusion variant in a patient with metastatic lung adenocarcinoma and a remarkable response to crizotinib. Lung Cancer Apr. 2020;142:59-62. doi:https://doi.org/10.1016/j. lungcan.2020.02.012.

5. Kuroda N, Trpkov K, Gao Y, et al. ALK rearranged renal cell carcinoma (ALKRCC): a multi-institutional study of twelve cases with identification of novel partner genes CLIP1, KIF5B and KIAA1217. Modern pathology: an official journal of the United States Canadian Academy of Pathology Inc Dec. 2020; 33(12):2564-79. doi:https://doi.org/10.1038/s41379-020-0578-0.

6. Yang C, Zhang L, Love-Gregory L, Sun L, Hagemann IS, Cao D. Identification of novel ALK rearrangements in gynecologic clear cell carcinoma. International journal of cancer Jan. 2021;15(2):459-68. doi:https://doi.org/1 0.1002/ijc.33330. 148 )

7. Yakirevich E, Resnick MB, Mangray S, et al. Oncogenic ALK Fusion in Rare and Aggressive Subtype of Colorectal Adenocarcinoma as a Potential Therapeutic Target. Clinical cancer research: an official journal of the American Association for Cancer Research Aug 1. 2016;22(15):3831-40. doi: https://doi.org/10.1158/1078-0432.CCR-15-3000.

8. Hung YP, Dong F, Watkins JC, et al. Identification of ALK Rearrangements in Malignant Peritoneal Mesothelioma. JAMA oncology Feb. 2018;1(2):235-8. doi:https://doi.org/10.1001/jamaoncol.2017.2918. 4 )

9. Shaw AT, Kim DW, Nakagawa K, et al. Crizotinib versus chemotherapy in advanced ALK-positive lung cancer. The New England journal of medicine Jun. 2013:20(25):2385-94. doi:https://doi.org/10.1056/NEJMoa1214886. 368).

10. Friboulet L, Li N, Katayama R, et al. The ALK inhibitor ceritinib overcomes crizotinib resistance in non-small cell lung cancer. Cancer Discov Jun. 2014; 4(6):662-73. doi:https://doi.org/10.1158/2159-8290.CD-13-0846.

11. Shaw AT, Gandhi L, Gadgeel S, et al. Alectinib in ALK-positive, crizotinibresistant, non-small-cell lung cancer: a single-group, multicentre, phase 2 trial. Lancet Oncol Feb. 2016;17(2):234-42. doi:https://doi.org/10.1016/S14 70-2045(15)00488-X.

12. Kim DW, Tiseo M, Ahn MJ, et al. Brigatinib in Patients With CrizotinibRefractory Anaplastic Lymphoma Kinase-Positive Non-Small-Cell Lung Cancer: A Randomized, Multicenter Phase II Trial. Journal of clinical oncology: official journal of the American Society of Clinical Oncology Aug. 2017;1(22):2490-8. doi:https://doi.org/10.1200/JCO.2016.71.5904. 35 ). 
13. Wu X, Zhou H, He Z, et al. Coexistence of a novel CCNY-ALK and ATIC-ALK double-fusion in one patient with ALK-positive NSCLC and response to crizotinib: a case report. Translational lung cancer research Dec. 2020;9(6): 2494-9. doi:https://doi.org/10.21037/tlcr-20-1049.

14. Wu X, Wang W, Zou B, et al. Novel NLRC4-ALK and EML4-ALK double fusion mutations in a lung adenocarcinoma patient: A case report. Thorac Cancer Jun. 2020;11(6):1695-8. doi:https://doi.org/10.1111/1759-7714.13389.

15. Luo J, Gu D, Lu H, Liu S, Kong J. Coexistence of a Novel PRKCB-ALK, EML4ALK Double-Fusion in a Lung Adenocarcinoma Patient and Response to Crizotinib. J Thorac Oncol Dec. 2019;14(12):e266-8. doi:https://doi.org/10.101 6/j.jtho.2019.07.021.

16. Qin BD, Jiao XD, Liu K, Wu Y, Zang YS. Identification of a Novel EML4-ALK, BCL11A-ALK Double-Fusion Variant in Lung Adenocarcinoma Using NextGeneration Sequencing and Response to Crizotinib. J Thorac Oncol Jun. 2019;14(6):e115-7. doi:https://doi.org/10.1016/j.jtho.2019.01.032.

17. Lin H, Ren G, Liang X. A Novel EML6-ALK FBXO11-ALK Double Fusion Variant in Lung Adenocarcinoma and Response to Crizotinib. J Thorac Oncol Nov. 2018;13(11):e234-6. doi:https://doi.org/10.1016/j.jtho.2018.07.011.

18. Yin J, Zhang Y, Zhang Y, Peng F, Lu Y. Reporting on Two Novel Fusions, DYSF-ALK and ITGAV-ALK, Coexisting in One Patient with Adenocarcinoma of Lung, Sensitive to Crizotinib. J Thorac Oncol Mar. 2018;13(3):e43-5. doi: https://doi.org/10.1016/j.jtho.2017.10.025.

19. Childress MA, Himmelberg SM, Chen H, Deng W, Davies MA, Lovly CM. ALK Fusion Partners Impact Response to ALK Inhibition: Differential Effects on Sensitivity, Cellular Phenotypes, and Biochemical Properties. Mol Cancer Res Nov. 2018;16(11):1724-36. doi:https://doi.org/10.1158/1541-7786.MCR-18-01 71.

20. Rosenbaum JN, Bloom R, Forys JT, et al. Genomic heterogeneity of ALK fusion breakpoints in non-small-cell lung cancer. Modern pathology: an official journal of the United States Canadian Academy of Pathology Inc. May 2018;31(5):791-808. doi:https://doi.org/10.1038/modpathol.2017.181.

21. Kligys K, Claiborne JN, DeBiase PJ, et al. The slingshot family of phosphatases mediates Rac1 regulation of cofilin phosphorylation, laminin332 organization, and motility behavior of keratinocytes. J Biol Chem Nov. 2007;2(44):32520-8. doi:https://doi.org/10.1074/jbc.M707041200. 282 ) .

22. Li $M$, Zhao $H$, Zhang $X$, et al. Inactivating mutations of the chromatin remodeling gene ARID2 in hepatocellular carcinoma. Nat Genet Aug. 2011; 7(9):828-9. doi:https://doi.org/10.1038/ng.903. 43 ).

23. Hodis E, Watson IR, Kryukov GV, et al. A landscape of driver mutations in melanoma. Cell Jul. 2012;20(2):251-63. doi:https://doi.org/10.1016/j.cell.2012. 06.024. 150)

24. Manceau G, Letouze E, Guichard C, et al. Recurrent inactivating mutations of ARID2 in non-small cell lung carcinoma. International journal of cancer May. 2013;1(9):2217-21. doi:https://doi.org/10.1002/ijc.27900. 132) .

25. Solomon BJ, Mok T, Kim DW, et al. First-line crizotinib versus chemotherapy in ALK-positive lung cancer. The New England journal of medicine Dec. 2014:4(23):2167-77. doi:https://doi.org/10.1056/NEJMoa1408440. 371 )

26. Rothenstein JM, Letarte N. Managing treatment-related adverse events associated with Alk inhibitors. Current oncology Feb. 2014;21(1):19-26. doi: https://doi.org/10.3747/co.21.1740.

27. Girard N, Audigier-Valette C, Cortot AB, et al. ALK-rearranged non-small cell lung cancers: how best to optimize the safety of crizotinib in clinical practice? Expert review of anticancer therapy. Feb. 2015;15(2):225-33. https://doi.org/10.1586/14737140.2014.986103.

28. Dikopf A, Wood K, Salgia R. A safety assessment of crizotinib in the treatment of ALK-positive NSCLC patients. Expert opinion on drug safety. Mar 2015;14(3):485-93. doi:https://doi.org/10.1517/14740338.2015.1007040.

29. Del Valle MFF, Chang AY. Real world experience on treatment, outcome and toxicity of crizotinib in patients with anaplastic lymphoma kinase positive advanced non-small cell lung cancer. Journal of thoracic disease Sep. 2019;11(9):3864-73. doi:https://doi.org/10.21037/jtd.2019.09.15.

30. Novello S, Mazieres J, Oh IJ, et al. Alectinib versus chemotherapy in crizotinib-pretreated anaplastic lymphoma kinase (ALK)-positive non-smallcell lung cancer: results from the phase III ALUR study. Annals of oncology: official journal of the European Society for Medical Oncology Jun. 2018;1(6): 1409-16. doi:https://doi.org/10.1093/annonc/mdy121. 29 ).

31. Johung KL, Yeh N, Desai NB, et al. Extended Survival and Prognostic Factors for Patients With ALK-Rearranged Non-Small-Cell Lung Cancer and Brain Metastasis. Journal of clinical oncology: official journal of the American Society of Clinical Oncology Jan. 2016;10(2):123-9. doi:https://doi.org/10.12 00/JCO.2015.62.0138. 34 ).

\section{Publisher's Note}

Springer Nature remains neutral with regard to jurisdictional claims in published maps and institutional affiliations.
Ready to submit your research? Choose BMC and benefit from:

- fast, convenient online submission

- thorough peer review by experienced researchers in your field

- rapid publication on acceptance

- support for research data, including large and complex data types

- gold Open Access which fosters wider collaboration and increased citations

- maximum visibility for your research: over $100 \mathrm{M}$ website views per year

At BMC, research is always in progress.

Learn more biomedcentral.com/submissions 